\title{
O negro drama do rap: entre a lei do cão e a lei da selva
}

\author{
BRUNO ZEN I
}

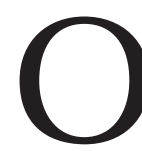

ÁLBU M DUPLO N ada comoum dia apóso outro dia (2002), a mais recente realização do grupo de rap Racionais M C's, é um disco violento e perturbador - como todos os anteriores na carreira do quarteto, formado por M ano Brown, Edy Rock, I ce Blue e KI J ay -, mas doloroso e tocante como nunca antes. D uas músicas excepcionais, "J esus chorou" e "N egro drama", retomam os temas recorrentes de suas letras: o cotidiano de violência hiperbólica da periferia descrito em longas letras de caráter narrativo e tom de revolta; a denúncia do preconceito racial contra os negros; um forte apelo religioso que faz da palavra instrumento de iluminação e conforto; um sentimento arraigado de pertencimento a uma determinada região da cidade de São Paulo, onde nasceu e vive o líder da banda, $\mathrm{M}$ ano Brown: a Zona Sul ${ }^{1}$ e al gumas de suas localidades, como o Capão Redondo e a Vila Fundão. Ao mesmo tempo, o disco apresenta uma face de lirismo, consciência da passagem do tempo e reflexão sobre a posição social do grupo que, se não é absolutamente inédita nas composições dos Racionais, ainda não havia aparecido de forma tão evidente e tocante.

$N$ egro drama é um rap de quase sete minutos, em que $E$ dy Rock e $M$ ano Brown revezam-se ao microfone. A voz grave e áspera do primeiro dá início à música:

N egro drama / entre o sucesso e a lama / D inheiro, problemas, inveja, luxo, fama / N egro drama / Cabelo crespo e a pele escura / a ferida, a chaga, à procura da cura / N egro drama / Tenta ver e não vê nada / a não ser uma estrela / longe, meio ofuscada / Sente o drama, o preço, a cobrança / no amor, no ódio, a insana vingança/ N egro drama/ Eu sei quem trama e quem tá comigo / o trauma que eu carrego / pra não ser mais um preto fodido / 0 drama da cadeia e favela / túmulo, sangue, sirene, choros e velas / Passageiros do Brasil, São Paulo / agonia que sobrevive / em meio a zorra e covardias / Periferias, vielas, cortiços / Você deve estar pensando o que você tem a ver com isso / D esde o início, por ouro e prata / olha quem morre, então veja você quem mata / Recebe o mérito a farda que pratica o mal / M e ver pobre, preso ou morto já é cultural [...]

A letra começa definindo uma situação geral, aquela de quem tem "cabelo crespo e a pele escura" : o drama de viver entre o sucesso e a lama é aquele dos negros brasileiros, mais especificamente dos negros das periferias de São Paulo, onde vivem os autores da música. 0 adjetivo "negro", anteposto ao "drama", 
assume também uma carga qualitativa negativa, mais metafórica - de escuridão, noite, treva -, que, no universo de forte religiosidade em que o grupo vive, traduz o medo da perdição. 0 verso "Tenta ver e não e vê nada" insere uma terceira pesso a na letra do rap, um personagem indeterminado - protagonista desse negro drama -, que tenta ver no horizonte algo como uma promessa de futuro, mas só vê um brilho pálido de estrela².

A terceira pessoa mantém o caráter generalizante da letra, mas a seguir, 0 "eu" assume voz para falar dessa experiência que é, ao mesmo tempo, comunitária e pessoal, o que o posiciona dentro do contexto que descreve. E dy Rock carrega consigo um trauma: um sentimento de cobrança para não ser mais um "preto fodido" (como dirá a letra mais adiante, ele está "sempre a provar que [é] um homem e não um covarde" ).

O s versos seguintes voltam a falar do drama geral, o drama da "cadeia" e da "favela", traduzido em signos concretos, sofridos e lúgubres como "túmulo, sangue, sirene, choros e velas". A música segue na alternância entre a voz em primeira pessoa e a construção da imagem do negro drama. Logo, porém, o rapper faz outro movimento, ao voltar-se diretamente ao ouvinte: "Você deve estar pensando o que você tem a ver com isso". A frase é endereçada a quem o escuta, mas certamente não aos negros, não àqueles que vivem o negro drama, a quem não ocorreria a dúvida de que o rapper suspeita haver em seu interlocutor. 0 verso parece expor a consciência de que, afinal, ele não fala apenas para os seus iguais, mas para uma população mais ampla, talvez a sociedade como um todo.

Além desse posicionamento que reflete uma consciência do lugar ocupado atualmente por eles, Racionais, no contexto social brasileiro, a letra compreende também sutis alusões ao processo histórico do país. É preciso estar atento aos dois lados da carnificina promovida no Brasil: "Olha quem morre, então veja você quem mata". D esde o início, diz E dy R ock, mata-se por "ouro e prata" , o que evidencia a correspondência com a história do Brasil, lugar onde, desde o início da colonização, houve aprisionamento e abate de carne negra e indígena, justificadas pela sede do capital - às vezes, literalmente, sede de ouro e prata, quando da descoberta do ouro nas M inas Gerais, no final do século XVII, mas também antes, durante o ciclo da cana-de-açúcar, e depois, nas lavouras de café, como atual mente na periferia das grandes cidades, segundo dizem os Racionais. Agora, porém, a violência contra os negros assume um caráter entre moral e selvagem, em que "recebe o mérito a farda que pratica o mal" . A referência à polícia, materializada na palavra" "farda”, é evidente, e a frase expõe a situação de conivência e incentivo com que é encarada a violência praticada contra a população pobre.

E dy Rock voltará a falar em nome próprio, agora de forma bastante afirmativa:

[...] Eu sou irmão dos meus trutas de batalha / Eu era carne, agora sou a própria navalha / Tim, tim..., um brinde pra mim / Sou exemplo de vitórias, trajetos e glórias / 0 dinheiro tira um homem da miséria / mas não pode arrancar de dentro dele a favela [...] 
O cantor dos Racionais acredita-se um exemplo de vitória e propõe a si mesmo um brinde solitário, que é a tomada de consciência íntima do seu percurso bem-sucedido. Saiu de uma posição de miséria, mas não teve a favela que há dentro dele arrancada de seu peito. C ontinua sendo irmão dos "trutas de batalha". A grande diferença, promovida talvez pelo sucesso que o grupo conquistou, é

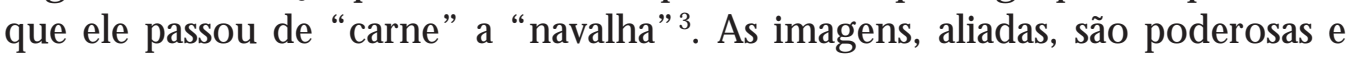
agressivas, e remetem, mais uma vez de forma alusiva, à história brasileira.

A segunda parte da mesma música é cantada por $\mathrm{M}$ ano Brown. $\mathrm{O}$ rapper introduz a sua fal a com algumas palavras que permitem aprofundar a compreensão do que é o negro drama:

C rime, futebol, música/ Eu também não consegui fugir disso / Eu sou mais um.

$M$ ano Brown é mais um a protagonizar o drama de quem nasce negro no B rasil: se escapar da lama, resta-lhe o "sucesso" - no crime, no futebol ou na música -, um sucesso que se dá, na opinião dos Racionais, de forma a contribuir com a manutenção do sistema de exclusão. Eles não fazem parte desse mecanismo. Ao contrário, eles se consideram o "efeito colateral do sistema", como diz a letra de "Capítulo 4, versículo 3", música do disco anterior, Sobreviven do no inferno. Por isso, a fala de $\mathrm{M}$ ano Brown ilustra, com sentimento de dor compartilhada, 0 negro drama vivido não apenas por quem é negro e os escuta, mas também por eles próprios, negros e artistas.

Por isso, por não ter conseguido fugir do drama de tantos negros - aquele de ser artista, de fazer música no Brasil -, Brown precisa, assim como E dy Rock na primeira parte da música, dirigir-se também àqueles que consomem música e arte no país. M ano Brown conta a sua própria história na segunda parte de "N egro drama" e, a certa altura da letra, volta-se, em tom acusatório, a um interlocutor específico:

Ei, senhor de engenho / eu sei bem quem vocêé / sozinho você num güenta / Você disse o que era bom / e a favela ouviu / uísque, Red Bull, tênis N ike, fuzil / [...] Seu jogo é sujo / e eu não me encaixo / eu sou problema de montão / de Carnaval a Carnaval / Eu vim da selva, sou leão / Sou demais pro seu quintal $[\ldots]$

De novo, o apelo à raiz histórica brasileira serve para reforçar o estrago contemporâneo da herança colonial e, por extensão, a persistência da lógica escravista. Foi o senhor de engenho quem ensinou a favela a sonhar com os bens de consumo e a cultivar o fascínio das armas. Sozinho, no mano a mano, o rapper sabe que o senhor de engenho não o enfrentaria: a classe dominante precisa da polícia e dos seus mecanismos de alienação. Brown diz que não se encaixa nesse jogo sujo, "ele é problema de montão de Carnaval a Carnaval". M ais adiante, Brown, ainda dirigindo-se ao senhor de engenho, vai mencionar o fato de a elite e a classe média também escutarem rap: "I nacreditável, mas seu filho me imita [...] Seu filho quer ser preto / Ah!, que ironia!". 
O rap dos Racionais pretende, ao que parece, levar a lei da selva que domina a periferia ao interior da casa grande, aos ouvidos da elite, com a certeza brutal com a agressividade que os afirma e protege - de que eles são demais para 0 quintal das classes dominantes. E, como afirmara E dy Rock antes, "me ver pobre, preso ou morto já é cultural". A denúncia do grupo não poderia ser mais grave: nós, pretos e pobres da periferia, vivemos segundo a lei da selva, lei esta que, apesar de absurda e violentadora, já foi incorporada à cultura brasileira, em que é normal ver os negros pobres, presos ou mortos.

Como se nota, o grupo atravessa um momento de reflexão profunda e expressão direta sobre a própria dimensão e so bre o papel que desempenha, especialmente entre os seus fãs e seguidores, mas também na sociedade como um todo. Formado em meados da década de 1980, os R acionais se tornaram, ao longo dos anos de 1990, o mais conhecido grupo de rap do país, com enorme popularidade na periferia das grandes cidades brasileiras e grande ressonância também na classe média. Especialmente a partir de 1997, quando lançam Sobrevivendo no inferno, os integrantes, suas letras e músicas se tornam nacionalmente conhecidos. O CD fez enorme sucesso - segundo a banda, foram vendidos mais de um milhão de exemplares do disco ${ }^{4}$ - e levou o rap a espaços antes pouco freqüentados pelo gênero: as rádios comerciais, a TV e os toca-discos da classe média branca.

O sucesso dos Racionais não é caso único no rap. O utros grupos que começaram mais ou menos na mesma época, como a dupla T haíde e DJ H um, gozam de grande notoriedade e similar admiração, mas os Racionais se tornaram um fenômeno específico por alcançar enorme popularidade tanto na periferia como na classe média intelectualizada sem abrir mão de um discurso combativo que, não raro, beira o incentivo ao enfrentamento racial e de classe. Além disso, o grupo adota postura radical quanto ao relacionamento com a grande imprensa, encarada com desconfiança, e quanto à integridade sonora do rap, feito de pouco diálogo com a tradição da música brasileira ${ }^{5}$.

De alguns anos para cá, porém, novos grupos e cantores de rap - se não têm questionado diretamente essa atitude de distanciamento dos Racionais em relação ao mainstream e à vida intelectual e artística brasileira - vêm atuando de forma mais aberta e receptiva ao diálogo. É o caso de nomes como o do rapper Sabotage, que participou de filmes brasileiros recentes como 0 invasor e C arandiru, e o de Rappin' H ood, cujo disco Sujeito homem (2001) conta com a participação dos emboladores pernambucanos Caju e Castanha e de sambistas como Lecy Brandão.

Sabotage, nome artístico de M auro M ateus dos Santos, um dos artistas mais interessantes que surgiram no rap nacional, foi assassinado no começo de 2003, aos 29 anos. A morte, inesperada e ainda não esclarecida, foi uma perda irreparável, sentida em níveis diversos: tanto no plano artístico quanto na esfera pessoal e afetiva, deixando inconsoláveis aqueles que o conheciam, conquistados por sua simpatiza e gentileza. 


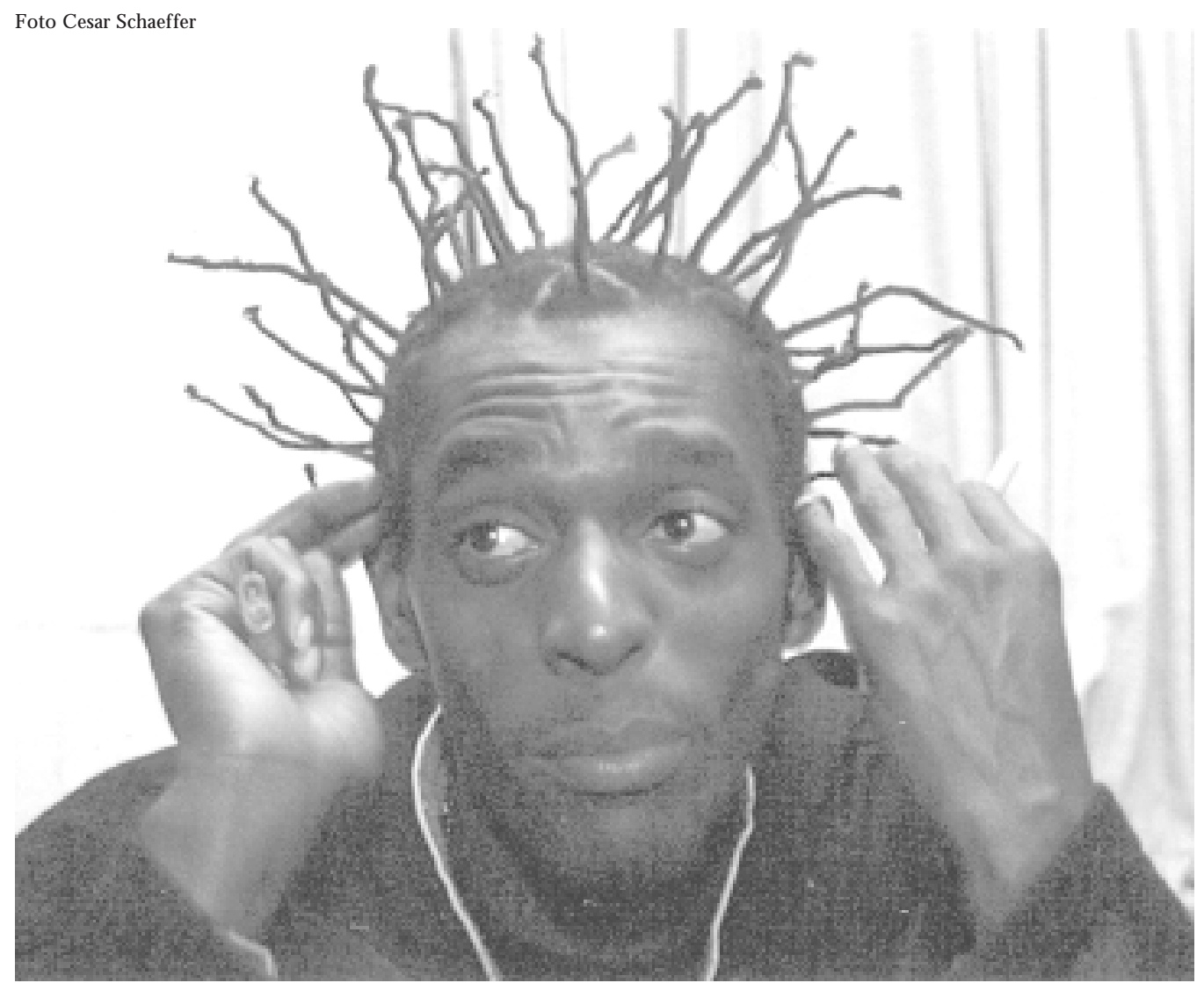

O rapper Mauro M ateus dos Santos, o Sabotage, foi mor to com quatro ti ros em São Paulo.

Além de familia-res do cantor, o enterro de Sabotage - cerimônia à qual compareci mesmo sem tê-lo conhecido pessoalmente - reuniu os principais nomes do rap de São Paulo, e foi acompanhado também por integrantes do coletivo Instituto, grupo com quem Sabotage vinha trabalhando, por VJs da MTV, por jornal istas da grande imprensa e por pessoas ligadas ao cinema nacional, como 0 diretor Beto Brandt.

Sabotage, que havia lançado o disco R ap écompromisso (2001), não conseguiu sobreviver às imposições da lei da selva, mas suas composições - que aliavam protesto, alegria e bom humor - deixam aos que seguem na luta diária nesta terra uma cintilação de esperança: num contexto dominado pela lógica letal da violência ligada ao tráfico e ao crime organizado, é possível falar de amor, amizade, música e arte, sem perder a consciência da desigualdade e da dor.

\section{B reve história do movimento}

0 movimento hip hop brasileiro já tem cerca de vinte anos, massua trajetória - e aquela de seus integrantes - ainda não foi contada de forma consistente e sistematizada. D ispersa e pouco registrada, a história dessa manifestação cultural que compreende música, dança, poesia, artes plásticas e mobilização social apenas começa a ser organizada em relatos e estudos que comportam diversas áreas do 
conhecimento, como a sociologia, a antropologia, a pedagogia, a psicologia, o jornalismo e as letras - a abrangência de abordagens e de enfoques a respeito do tema dá a medida da riqueza e da complexidade do fenômeno.

O hip hop se constitui de quatro elementos: o break (a dança de passos robóticos, quebradose, quando realizada em equipe, sincronizados), o grafite (a pintura, normalmente feita com spray, aplicada nos muros da cidade), o DJ (o disc-jóquei) e o rapper (ou M C, mestre de cerimônias, aquele que canta ou declama as letras so bre as bases el etrônicas criadas e executadas ao vivo pelo DJ ). A junção dos dois últimos elementos resulta na parte musical do hip hop: o rap (abreviação de rythym and poetry, ritmo e poesia, em inglês). Alguns integrantes do movimento consideram também um quinto elemento, a conscientização, que compreende principal mente a valo rização da ascendência étnica negra, o conhecimento histórico da luta dos negros e de sua herança cultural, o combate ao preconceito racial, a recusa em aparecer na grande mídia e o menosprezo por valores como a ganância, a fama e o sucesso fácil. C ertos grupos reúnem-se em posses, associações que têm por objetivo organizar o movimento, tanto do ponto de vista musical como social, disponibilizando para a comunidade aulas de hip hop e de outras matérias, como educação sexual, informática, cultura negra ehistória, por exemplo.

O s cinco elementos completam-se e influenciam-se, mas podem manifestarse de forma independente, a partir de interações as mais diversas. É possível, por exemplo, que antes de um show de rap aconteçam apresentações de gangues (equipes) de break, e grafiteiros exercitem suas habilidades nas paredes do local, sem que seja necessário, porém, que todos os elementos aconteçam ao mesmo tempo. A pesar de independentes uns dos outros, os rappers, DJ s, grafiteiros e bboys (dançarinos de break) se sentem irmanados, e alguns deles podem desempenhar mais de uma função. Antes de começarem a fazer rap, Thaíde e DJ H um, dupla pioneira do movimento hip hop brasileiro, por exemplo, integravam uma gangue de break, a Back Spin.

Em tradução literal, a expressão de língua inglesa "hip hop", significa pular e mexer os quadris. H istoricamente, foi cunhada pelo DJ Africa Bambaataa no final da década de 1960 para designar as festas de rua no bairro do Bronx, em $\mathrm{N}$ ova York, maciçamente freqüentadas por jovens negros. $\mathrm{N}$ aquela época, a música ouvida nessas festas era o soul, que logo evoluiria para um desdobramento mais agressivo, o funk - os dois ritmos são os antepassados do rap. No funk, o nome mais conhecido é o de James Brown, em cujos shows, por volta de 1969, apareceram os primeiros passos da dança que viria a ser conhecida como break ${ }^{6}$.

A história do hip hop está ligada, desde a sua origem, às lutas e conquistas políticas dos negros norte-americanos nos anos de 1960. Como lembra o jornalista Spensy Pimentel, em seu trabal ho de conclusão de curso 0 livro vermelho do hi p hop, dois líderes negros americanos foram assassinados naquela década: $M$ alcolm X, em 1964, e M artin L uther King, em 1968. Aslutas dos negros contra discriminação e por maior participação política, duramente reprimidas durante o período, 
evoluíram para estratégias mais agressivas, como aquelas empreendidas por organizações como os Black Panthers(Panteras N egras). C omo registra ainda Spensy Pimentel, a mãe de Tupac Shakur - um dos principais rappers americanos, assassinado em 1996 foi integrante dos Panteras N egras? ${ }^{7}$.

O s primeiros discos de rap começaram a aparecer no final da década de 1970, mas o primeiro grande sucesso comercial do ritmo foi o disco $\mathrm{R}$ aising $\mathrm{H}$ el (1986), do grupo americano Run D M C. Ao longo da década de 1980 começam a surgir também os grupos de postura mais agressiva, como N WA (N iggers with Attitude) e Public Enemy.

N o Brasil, os chamados bailes black eram comuns desde os anos de 1970, animados por músicas soul e funk, principalmente em São Paulo, no Rio de Janeiro, em Salvador e em Brasília. M ilton Salles, ex-produtor dos Racionais, organizava bailes Black Power em São Paulo desde aquela década.

0 hip hop surgiu em São Paulo em meados da década seguinte. As primeiras manifestações foram realizadas por volta de 1984, no centro da cidade, na região da estação São Bento do metrô e nas ruas 24 de maio e D om J osé de Barros. 0 b-boy N elson Triunfo foi um dos primeirosa dançar break nas ruas de São Paulo. Vindo de Triunfo, Pernambuco, N elsão apenas chegara a São Paulo e já tinha uma companhia de dança de rua, a Funk \& Cia.

O rap surgiria como canto improvisado para acompanhar as manobras corporais do break. O s rappers cantavam na rua, improvisando ao som de latas, palmas e beat box (imitação das batidas eletrônicas feitas com a boca). N o começo, por ser um canto falado, feito de improviso nas rodas de break, o rap era chamado no Brasil de "tagarela". Como no começo havia também pouca preocupação com o conteúdo contestatório ou de protesto das letras, proliferou um tipo de rap inocente, descontraído e brincalhão, que mais tarde viria a ser conhecido como "rap estorinha", designação que trai certo desprezo pelo antigo estilo.

M uitos rappers vieram das gangues de break. É o caso de Thaíde, que, em 1984-1985, dançava na Back Spin, quando conheceu numa festa o DJ H umberto $\mathrm{M}$ artins. Juntos, formariam a dupla Thaíde e DJ H um, um dos primeiros grupos de rap brasileiro. O s discos de rap brasileiros começaram a ser gravados no final dos anos de 1980. Em sua maioria, eram coletâneas, em que figuravam vários grupos, de estilos diversos. Entre elas, destacam-se 0 som dasruas, Situation rap, Ousadia do rap, Consciência black (esta, já tinha presença dos Racionais M C's) e H ip H op - Cultura derua. N esta última, havia duas músicas de Thaíde eDJ H um: "Corpo fechado" e "H omens da lei". As duas composições, em que o rapper fala mal da polícia e chama a atenção para a lei do cão em que vivem os habitantes de São Paulo, são consideradas pioneiras do chamado rap "consciente" e de "atitude".

\section{A raça como estigma e como orgulho}

A relação entre o hip hop e os movimentos ligados à conquista de direitos civis pelos negros foi, como se disse, estreita durante os anos de criação e de pri- 
meiros passos do rap americano. 0 tema da discriminação e da opressão que recai sobre a raça negra foi, também, uma constante desde o começo do rap feito em São Paulo. Do início dos anos de 1990 até hoje, nota-se uma continuidade e um refinamento no trato dessa questão, que vai da postura agressiva e de enfren-tamento do início - como indicam al gumas primeiras das letras dos Racionais, como "Racistas otários" e "N egro limitado" - até uma atitude mais afirmativa, de orgulho de ser negro, como mostram as letras de Rappin' Hood "Sou negrão" e "Tributo às mulheres pretas", do CD Sujeito homem. 0 uso do termo "preto", aliás, é bastante difundido e aceito entre a maioria dos rappers, que se apropriaram da palavra de forma a transformá-la de designação depreciativa em motivo de orgulho.

As letras da dupla Thaíde e DJ H um também percorrem um caminho deliberadamente construtivo e de escopo, digamos, esclarecedor. Presteatenção, disco de 1997, começa com a seguinte "Intro", declamada por Thaíde num registro que está entre a fala e o canto, sobre as bases rítmicas de DJ H um:

$\mathrm{N}$ a África existe uma irradiante luz negra / Falo do meu povo / Falo da minha gente / Nada pode me parar / Vamo que vamo / Vivo nas ruas com minha liberdade / DJ H um, faz scratchs / Somos descendentes de Zumbi, grande guerreiro / H ip hop na veia / Algo vai mudar / Deus existe para todos [...]

Zumbi dosPalmares tornou-se uma referência fortíssima para todo o universo do hip hop, de forma a lembrar a luta contra a escravidão e a necessidade de se conscientizar sobre a herança colonial brasileira, que ainda projeta suas se-qüelas sobre a sociedade contemporânea. O grupo de rap Z'África Brasil gravou, em 2002, um disco intitulado A ntigamentequilombos, hojeperiferia. $O$ " $Z$ " que precede o nome do continente negro é a inicial de Zumbi. A música "A cor que falta na bandeira brasileira" relembra os quinhentos anos de história sangrenta do Brasil: 0 vermelho do sangue, diz a letra, é a cor que falta à bandeira de um país que dizimou sua população indígena e promoveu uma carnificina contra a população negra.

0 tom aqui é, como nas letras dos Racionais, de revolta. A faixa que dá nome ao disco diz: "Levante as caravelas, aqui não daremos trégua, não / então que venha a guerra / Zulu África Zumbi". O grupo, porém, faz também raps de caráter mais festeiro, de convite à alegria e ao divertimento, em letras como "Sapo na banca" ou "M ano chega aí", cujo refrão, cantado alternadamente por uma voz feminina e por um coro, é "Q uem diz que na periferia não dá curtir? / M ano chega aí, mano chega aí", convidando o ouvinte para uma festa de hip hop. A letra lembra da preciosidade dos momentos de festa e recomenda ao mano que "descanse o seu gatilho", pois "aqui não é bangue-bangue".

Z'África Brasil conjuga protesto e humor, diversão e conscientização, descontração e incitamento ao levante - isto é, à luta do dia-a-dia. A "guerra" a que o grupo convoca, parece-me, é metáfora para a situação de penúria a que os moradores da periferia estão submetidos, essa mesma situação de miséria e violência que transformou a periferia num inferno em que vigora a lei da selva, como repetem as letras dos Racionais. D e acordo com o que o Z 'África Brasil assevera, 
porém, no quilombo contemporâneo, a luta contra a escravidão é compartilhada tanto por negros quanto por brancos, situação que a constituição do grupo reflete de forma interessante: os do is principais letristas e cantores do grupo são o M C Gaspar, branco, e o M C Funk Buia, negro.

No disco Presteatenção (1997), de Thaíde e DJ H um - da mesma forma, o primeiro mulato e o segundo branco - outra música relembra a importância de ser "negro por inteiro, reconhecendo o seu valor, e por favor, respeitando o irmão mais claro, que está sempre do seu lado". O rap se chama "Afro-brasileiro".

Sabe quem eu sou? / Afro-brasileiro / Somos descendentes de Zumbi, grande guerreiro.

A expressão "afro-brasileiro" do refrão é cantada em coro, por mais de uma voz, de forma a sublinhar a condição coletiva e de mobilização que a letra apresenta. A composição também chama a atenção para a importância das religiões africanas. Thaíde se diz filho de O gum e I emanjá e afirma: "sou um preto atrevido gosto quando me chamam de macumbeiro, toco atabaque em rodas de capoeira". 0 verso que antecipa a volta do refrão é "o meu orgul ho é ser um negro verdadeiro".

Como sempre nas composições da dupla, ainda que a letra do rap seja incisiva, a musicalidade é rica. 0 ritmo é de funk, a batida é positiva, eThaíde faz, de forma expressa, um convite à dança e à cel ebração. É do mesmo disco, aliás, uma das mais conhecidas e al egres composições do rap brasileiro, "Sr. Tempo Bom". A letra fala de um tempo bom, que não volta mais, aquele da infância do M C , da década de 1970 - com referência a, entre outros, Jorge Ben e Tim M aia - e o do começo do movimento hip hop nacional, aquele das rodas de break da estação São Bento. A pesar do horizonte nostálgico, a música é de uma alegria contagiante, que culmina nos vocais femininos po derosos de Paula L ima el eda H ills. A música presta homenagem àqueles que curtiram o black power e celebra a continuação do es-pírito de contestação e determinação dos anos de 1970 no atual movimento hip hop.

\section{R ap e universo carcerário}

A situação social da população brasileira de baixa renda se agravou nosúltimos trinta anos, e a imensa presença de homens de pele negra no sistema penitenciário do país é indício de que a desigualdade de classe continua a ser sentida de maneira mais grave entre os negros.

A relação do rap com o universo prisional é de intimidade e reciprocidade. Por ser uma música surgida entre a população pobre, o rap tem, na grande massa carcerária brasileira, composta majoritariamente de negros e pobres, um público fiel e rapper em potencial. 0 movimento é de mão dupla: o rap tematiza o mundo da cadeia, ponto final daqueles que se envolvem com o crime e com a violência ameaça vivida de forma próxima e intensa por grande parte dos moradores da periferia -, e as prisões produzem rap. 
O s Racionais já haviam abordado o tema em "O homem na estrada" - a música descreve o cotidiano de um ex-presidiário que tenta reconstruir sua vida. "Diário de um detento", porém, é um rap excepcional, por conta da maneira com que a música é elaborada, pelo conteúdo temático de sua letra - o massacre do Carandiru - e também pela qualidade da construção literária da composição.

O rap descreve os acontecimentos daquele que foi a maior chacina da história das prisões brasileiras. A letra foi composta numa parceria entre $M$ ano Brown e 0 ex-detento J ocenir, que, à época de lançamento do disco, ainda estava preso na C asa de D etenção de São Paulo, o presídio do Carandiru, desativado em 2002. O líder dos Racionais costumava visitar o presídio com freqüência e, durante uma de suas visitas, soube da existência de um detento que escrevia poemas e letras de música. Brown pediu para conhecer o preso e, depois de dar uma olhada nos seus cadernos de anotação, saiu da D etenção com algumas páginas escritas por J ocenir. A partir dessas anotações, Brown compôs a letra do rap.

"Diário de um detento" narra, por meio da voz de um presidiário, os acontecimentos do dia 2 de outubro de 1992, dia do massacre do Carandiru. A letra, porém, comporta também os dias que precedem a chacina e os que a seguem, o que aprofunda o teor dramático da letra. 0 detento narra o desenrolar do massacre desde o dia anterior e termina a letra do rap no dia seguinte, como um sobrevivente da carnificina. 0 ponto de vista interno - é um detento narrando os acontecimentos dos dias 1o , 2 e 3 de outubro de 1992 - já seria algo inusitado e digno de atenção, mas sobressai na letra também a capacidade de organizar experiência pessoal, funcionamento da indústria cultural e uma grande consciência política, expressa na dúvida sobre possibilidade de se fazer ouvir, sobre o crédito que teria sua voz na sociedade em que está inserida.

É o que fica patente em alguns dos versos da música:

E ra a brecha que o sistema queria / Avisa o IM L chegou o grande dia [...] Cachorros assassinos, gás lacrimogênio / Q uem mata mais ladrão ganha medalha de prêmio [...]

O ser humano é descartável no Brasil, como modess usado ou bombril [...]

C adeia apaga o que o sistema não quis / E sconde o que a novela não diz [...]

Cadáveres no poço, no pátio interno / Adolf $\mathrm{H}$ itler sorri no inferno [...]

Ratatatá / Fleury e sua gangue vão nadar numa piscina de sangue [...]

$M$ as quem é que vai acreditar no meu depoimento? D ia 3 de outubro, diário de um detento.

As frases finais da música, declamada por M ano Brown, deixavam no ar uma pergunta incômoda sobre a capacidade de convencimento daquele que depõe e diz que houve ali uma matança. $\mathrm{O}$ u melhor, o rap questiona o silenciamento a que são submetidos historicamente no país os presidiários, mas também os pretos, os pobres e todas as vítimas da opressão. A contundência da letra é sensível, e a maneira com que a música acaba, com uma pergunta que não quer calar - "Q uem 
é que vai acreditar no meu depoimento?" - estabelece um desafio, ecoando a lembrança de que a ferida do M assacre continuava então aberta.

Ao longo dos anos seguintes, a literatura brasileira viu surgir al guns livros que registram outros depoimentos de detentos sobre a própria vida nas prisões brasileiras ${ }^{9}$. 0 livro precursor dessa leva de literatura prisional, porém, não é de autoria de um presidiário, mas de um médico que desenvolveu um trabalho voluntário na C asa de D etenção de São Paulo: o best-seller Estação C arandiru (1997), de autoria D rauzio Varella. D epois vieram, entre outros, Diário de um detento (2001), de Jocenir (o co-autor, com M ano Brown, do rap de mesmo nome), M emórias deum sobrevi vente(2001), de L uiz Alberto M endes, e SobreviventeA ndrédu R ap (2002), que escrevi em parceria com J osé André de Araújo, que estava no Pavilhão N ove do Carandiru no dia 2 de outubro de 1992 e sobreviveu ao M assacre. No livro, André descreve a ação da polícia naquele dia e fala dos quase dez anos que ficou preso, em inúmeras penitenciárias do Estado de São Paulo. André du Rap, nome artístico do autor, encontra-se atualmente em liberdade e procura meios para gravar o seu primeiro CD de rap.

A privação de liberdade, apesar de ser um forte empecilho aos que pretendem desenvolver qualquer tipo de atividade que escape à rotina opressiva da cadeia, não impediu que alguns detentos publicassem livros e que al guns grupos de rap não apenas se formassem dentro do sistema penitenciário brasileiro como conseguissem gravar discos na cadeia.

O grupo D etentos do Rap, formado na Casa de D etenção de São Paulo, gravou em 1998, o primeiro CD da carreira, A pol ogia ao crime. No ano seguinte, lançaria mais um CD , 0 pesadel o continua. O utro grupo formado no $C$ arandiru é bastante conhecido: chama-se 509-E e é formado por D exter e Afro-X, que também gravaram dois discos: Provérbi os 13 e M MII . O nome do grupo faz referência ao número da cela que dividiam no Pavilhão Sete da D etenção. Em 1999, um dos bandidos mais famosos do país também estreou no rap: J osé Carlos dos Reis Encina, o Escadinha, gravou o disco Fazendo justiça com as própriasmãos. Em 2002, outro grupo conseguiu gravar um CD dentro do Carandiru: o Comunidade C arcerária, com o qual André du Rap ensaiava durante sua estada na cadeia.

$O$ utro nome de destaque da literatura brasileira recente é o escritor e rapper Ferréz, morador do Capão Redondo, zona sul de São Paulo, mesma área de M ano Brown. $O$ líder dos Racionais é, aliás, um dos inúmeros rappers que contribuíram com depoimentos que integram o primeiro livro de Ferréz, Capão pecado (2000). Trata-se de um romance, mas o livro tem fotos do C apão redondo, onde a história se desenvolve, além de uma série de relatos de "aliados" - todos moradores de bairros periféricos - que endossam a "veracidade" do que está sendo dito ali. A narrativa é protagonizada por Rael, rapaz que começa a história trabal hando numa padaria. Troca de emprego e passa a trabalhar numa fábrica. Paquera Paula, namorada do amigo $\mathrm{M}$ atcherros. A moça troca o companheiro por Rael. Ao descobrir que Paula o trai com o chefe da fábrica, Rael decide 
assassiná-lo. Vai parar na cadeia, onde também é morto, por encomenda de um matador que o havia ajudado no assassinato que cometera.

O nível de violência cresce de forma contínua ao longo do livro, até arrastar todos os personagens a um ajuste de contas sem fim, em que as pessoas se matam por motivação moral, para defender a honra, por dinheiro ou sem razão clara, talvez por prazer ou para se prevenir de uma possível retaliação motivada por pecad os cometidos anteriormente. Esse território sem lei que é o C apão R edondo retratado no romance, onde se morre e se mata de forma convulsiva e exacerbada, é também um lugar dominado pela lei do cão, em que o pecado e a perdição são norma, não exceção. 0 sentido crítico desse retrato, que mimetiza a desordem do real, ainda precisa ser devidamente avaliado, mas o aviso de que os bairros pobres de São Paulo se tornaram um espaço em que a morte acontece em escala industrial soa por demais urgente para não ser ouvido. Encontrar uma expressão estética que elabore a resistência a essa situação, e não apenas a denúncia - que pode resvalar para a estetização do problema -, parece ser a necessidade mais premente que se impõe aos novos artistas da periferia.

\section{M úsica de resistência à tentação do consumo}

N o mesmo ano de 1997, em que Thaídee DJ H um lançavam Presteatenção, aparecia Sobrevivendo no inferno, o quarto disco dos Racionais M C's, em que figuravam músicas como "D iário de um detento", "Rapaz comum", "Capítulo 4, versículo 3". As letras dos raps eram como uma rajada de metralhadora no cenário musical brasileiro. 0 disco é composto de doze faixas, mais de setenta minutos de som - uma mistura de música e poesia bruta, vinhetas, samplers (apropriações e colagens sonoras), letras agressivas declamadas de forma ritmada em composições extensas, que chegavam a mais de dez minutos, sem refrão ou repetições.

O s Racionais já eram bem conhecidos de quem acompanhava de perto as últimas novidades da música brasileira, mas o lançamento de Sobrevivendo no inferno projetou o grupo de forma definitiva no panorama da cultura brasileira da década. 0 disco é uma crônica virulenta sobre o cotidiano dos moradores da periferia de São Paulo, especialmente sobre o convívio diário com a violência, as drogas, as armas e a morte na zona sul da cidade (onde nasceram e moram dois dos integrantes do grupo, $M$ ano Brown e I ce Blue; os dois outros integrantes, Edy Rock e KI J ay são da zona norte de São Paulo).

A introdução de algumas músicas do disco, procedimento comum em diversos ál buns de rap, combina sons "reais" - como tiros, sirenes de carros da polícia e freadas de pneus - à voz do rapper. E o que ele diz em "G ênesis (I ntro)" não é, assim como a trilha sonora transportada diretamente da realidade, leve nem agradável: "Eu tenho uma bíblia velha, uma pistola automática e um sentimento de revolta. Estou tentando sobreviver no inferno." 


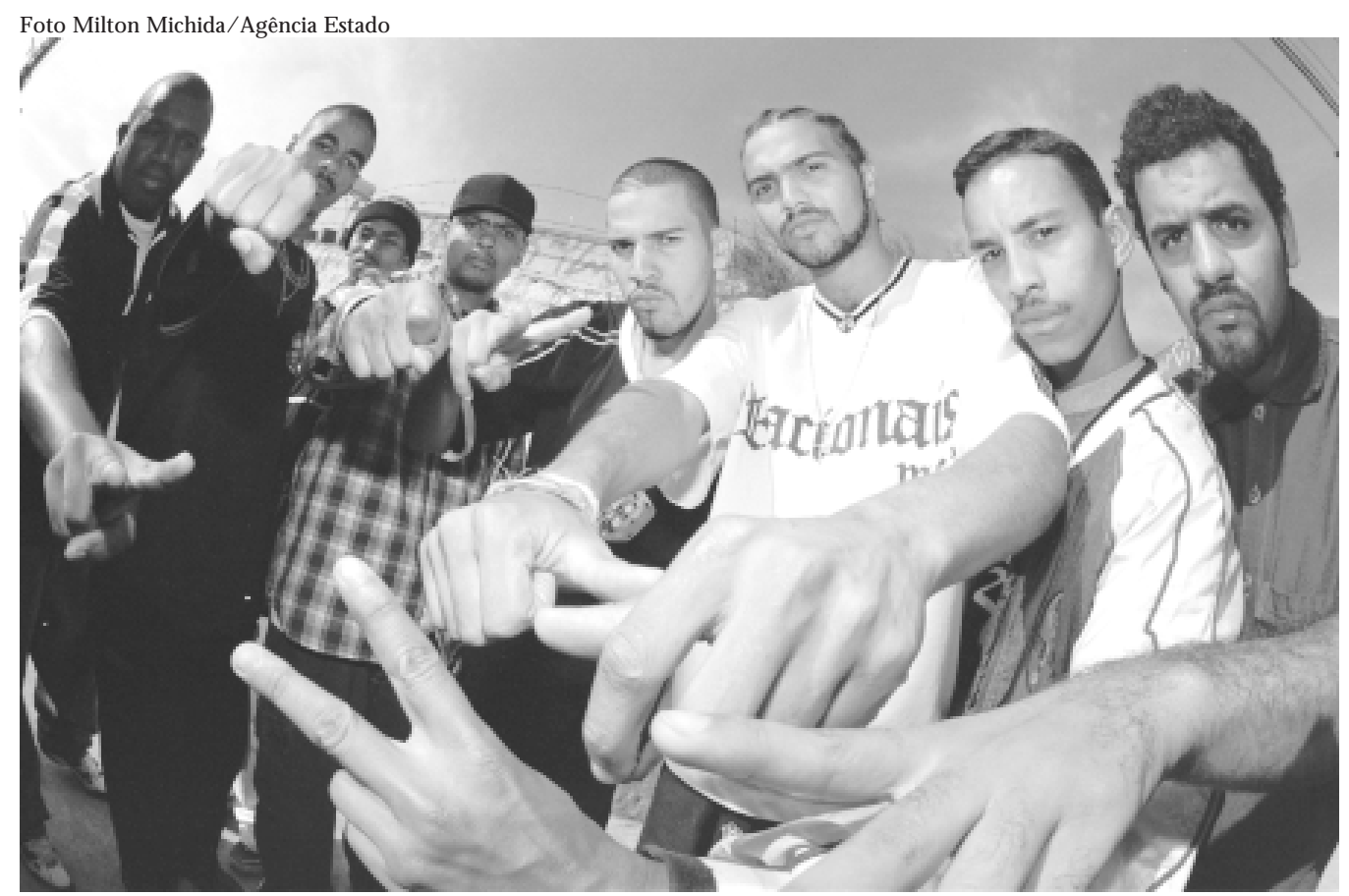

Gravação de vídeo clip do grupo C onexão do M or ro, com a partici pação de M ano Brow.

"C apítulo 4, versículo 3", uma das músicas mais fortes do disco e da história do grupo, apresenta um discurso de grande proximidade com o universo da violência e do crime. 0 procedimento, desconcertante, é o de identificar aquele que fala, ou seja, o eu lírico da música, ora ao próprio rapper, ora a um bandido. Sob o título generalizante, de recorte bíblico, que faz referência à história do grupo (trata-se da terceira faixa do quarto disco dos Racionais), "Capítulo 4, versículo 3" fala de um sujeito que carrega aquele sentimento de revolta por habitar a "fronteira do céu com o inferno":

$M$ inha intenção é ruim / esvazia o lugar / Eu tô em cima, eu tô a fim / um, dois pra atirar / Eu sou bem pior do que você tá vendo / 0 preto aqui não tem dó / é $100 \%$ veneno [...] M eu estilo é pesado e faz tremer o chão / minha palavra vale um tiro / e eu tenho muita munição [...]

O começo da música dá a entender que um criminoso, armado, toma de assalto um "lugar", que precisa ser esvaziado, a fim de não machucar ninguém. O preto que fala é cruel: "100\% veneno". A seguir, porém, ele apresenta sua arma: é o verbo. Cada palavra vale um tiro e sua munição é muita, como ele diz e se perceberá pela extensão da letra.

A música cunha imagens contraditórias e agressivas: aquele que canta diz que talvez seja um sádico, um anjo, um bandido do céu, franco atirador se for necessário, revolucionário, terrorista da periferia. "V iolentamente pacífico", diz que veio para "sabotar seu raciocínio", para "abalar o seu sistema nervoso e sangüíneo". E le se volta ao ouvinte, aquele que é seu igual e seu inimigo, aquele 
a quem pretende aconselhar ao mesmo tempo que confundir, sabotando o raciocínio, abalando os sistemas vitais.

M ano Brown, aquele que fala, estabelece também um diálogo com I ce Blue, outro dos integrantes dos Racionais, que chama a atenção do companheiro para um grupo que na noite anterior cheirava cocaína na beira do asfalto. "De cocaína e crack, uísque e conhaque, os manos morrem rapidinho sem lugar de destaque", diz I ce Blue. Brown responde aos versos do amigo dirigindo-se a um interlocutor, que pode ser tanto os personagens do rap quanto o ouvinte, pra dizer o seguinte:

Você vai terminar tipo o outro mano lá / que era um preto tipo A / N inguém entrava numas/ M ó estilo: de calça Calvin Klein, tênisPuma/ um jeito humilde de ser, no trampo e no rolê / Curtia um funk, jogava uma bola, buscava a preta dele no portão da escola / Exemplo pranós, mó moral, mó ibope / M as começou a colar com os branquinhos do shopping... [...]

A companhia dos branquinhos do shopping faz o "preto tipo A" desandar e o transforma num "neguinho", como dirá a letra mais à frente. 0 apelo do consumo, do qual os branquinhos são os protagonistas, é uma tentação e sucumbir a ela pode rebaixá-lo da classe $A$, do seu jeito humilde de ser, para a soberba da ganância e da cobiça. A insistência cínica da publicidade, que se impõe sem peias num país miserável, remete novamente àquele sentimento de revolta anunciado na introdução do disco.

Para os manos da Baixada Fluminense à Ceilândia, eu sei / as ruas não são como a Disneylândia / D e Guaianazes ao extremo sul de Santo Amaro / ser um preto tipo A custa caro / É foda! Foda é assistir a propaganda e ver / não dá pra ter aquilo pra você.

Aqui, em 1997, parece-me que o negro drama que apareceria de forma complexa no disco de 2002, já estava diagnosticado, mas talvez ainda não tivesse encontrado a sua formulação precisa - aquela que inclui no coração do drama, de forma explícita, os próprios membros do grupo. 0 desejo provocado pela publicidade, nunca satisfeito, esse parâmetro de felicidade de alcance improvável, é apontado nessa música como o perigo que leva ao descaminho, seja na Baixada Fluminense, Rio de J aneiro, seja na Ceilândia, cidade satélite de Braślia, seja na imensa periferia L este-Sul de São Paulo.

A alusão à sede do consumo eà fome da posse, interditadas aos despossuídos, lembra uma passagem de um conto de João Antônio, escritor que pode ser considerado um precursor do tipo de literatura que assistimos florescer hoje na periferia de São Paulo. "Paulinho Perna Torta", texto de 1965 incluído no livro Leão-de-chácara (1975), é um conto longo, narrado em primeira pessoa pelo bandido cuja alcunha dá título ao texto. Perna Torta relembra sua trajetória de formação na malandragem e no crime, com direito a uma passagem pela C asa de D etenção. Recordando os primeiros tempos de juventude, quando era engraxate 
nas estações da L uz e Julio Prestes, Perna Torta diz que cedo aprendeu que a ele, menino pobre, as pretensões de acumulação material não deveriam passar de fantasia.

"[...] me ensinaram que meu negócio era ver e desejar. Parasse aí." 10

Paulinho Perna Torta não parou, seguiu na "vida loka" do crime até se tornar rei da boca do lixo paulistana como cafetão, traficante e gerente de jogo. O desfecho dessa narrativa de ficção de J oão Antônio, porém, aponta para uma tomada de consciência do protagonista, que se questiona sobre a conduta de todos aqueles anos de criminalidade. A reflexão que acorre ao pensamento de Perna Torta a propósito de sua vida no crime talvez possa ser vista como um presságio do que aconteceria cerca de trinta anos depois, quando, hoje, começamos a ouvir relatos similares, agora não-ficcionais, de homens que percorreram trajetórias marcadas pela ilegalidade e pela criminalidade e que encontraram no rap e na literatura uma forma de expressar suas dores, suas dúvidas e seus desejos nunca satisfeitos.

\section{N otas}

1 U m lugar onde há "um coração ferido por metro quadrado", como diz a letra de "V.L.", música do mesmo disco. As iniciais V.L. abreviam "vida loka" (assim mesmo, com " $k$ " ), expressão que, na gíria da periferia, refere-se à vida no crime.

2 A imagem me lembra al gumas passagens do R ecordações do escri vão I saías C aminha, de Lima Barreto, e de poemas de Cruz e Sousa, como "O emparedado". O s dois escritores também viveram uma espécie de negro drama: sem lugar no mundo dos homens, isto é, na sociedade, encontraram refúgio para a própria solidão em imagens como a da vastidão do mar e a da imensidão cósmica.

3 A mudança de atitude que os R acionais propõem, da passividade à expressão da própria realidade e ao protesto, é sublinhada por M aria Rita Kehl no ensaio "A fratria órfã", ensaio do livro Função fraterna. $O$ texto de $M$ aria Rita analisa o que a ensaísta chama de "esforço civilizatório do rap na periferia de São Paulo". Anterior ao lançamento do último disco dos Racionais, o ensaio examina algumas das letras do grupo.

4 A informação sobre os números de venda do disco está em $\mathrm{H}$ ip H op. A periferia grita, de J anaína Rocha, M irella D omenich e Patrícia Casseano.

5 Essa postura dos R acionais não é de to do intransigente ou isenta de contradições. Em 2003, o grupo participou do Ensaio da TV Cultura, um dos mais importantes programas de música da TV brasileira. Q uanto ao diálogo com a tradição da música nacional, ele se dá com um momento específico, o da música negra brasileira dos anos de 1970. 0 nome do grupo, por exemplo, faz referência a um disco de Tim M aia, o álbum duplo Tim Maia R acional, de 1975. O utras referências fortes são Cassiano, $\mathrm{H}$ yldon, Wilson Simonal e J orge Ben, de quem os Racionais fizeram uma versão de "J orge da Capadócia", música que abre o CD Sobrevi ven do no I nferno.

60 rap se consolidou nos bairros negros de N ova York, como o Bronx e o $\mathrm{H}$ arlem, mas chegou ali pelas mãos de um DJ chamado Kool H erk, de Kingston, J amaica. N o 
Bronx, foi aprimorado pelo DJ Grandmaster Flash, discípulo de H erk. A esse respeito ver H ermano Vianna, 1998 e Spensy Pimentel, 1997.

7 Sobre a relação entre os movimentos negros norte-americanos e o hip hop ver a tese de Elaine N unes de Andrade: M ovi mento negro juvenil: um estu do de caso sobrejovens rappers de São Bernardo do Campo, 1996.

8 A dúvida sobre a credibilidade do relato sobre uma experiência traumática é uma das principais preocupações da literatura de testemunho dos sobreviventes dos campos de concentração tanto quanto da crítica que dela se ocupa. Sobre o tema, ver o livro Catástrofe e representação, organizado por Arthur N estrovski e M árcio SeligmannSilva, e o meu ensaio "U ma voz sobrevivente", incluído em Sobrevivente A ndré du R ap, 2000.

90 fenômeno é novo: presos comuns não costumavam escrever suas experiências carcerárias de próprio punho. 0 notório antecedente dessa literatura são as M emórias do cárcere, de Graciliano Ramos, mas o escritor alagoano, além de ter sido um preso político, já era escritor consagrado quando redigiu seu testemunho.

10 J oão Antônio. "Paulinho Perna Torta", em Leão-dechácara, São Paulo, Cosac e Naify, 2001, p. 100.

\section{Bibliografia}

AN D RADE, Elaine N unes de. M ovimento negro juvenil: um estudo de caso sobre jovens rappers de São Bernardo do Campo. Dissertação de M estrado, São Paulo, FFL CH U SP, 1996.

ANT Ô N IO, J oão. Leão-dechácara. São Paulo, Cosac e N aify, 2001.

CASSEAN O , Patrícia, RO CH A, Janaína eD O M EN I CH , M irella. H ip hop - A periferia grita. São Paulo, Fundação Perseu Abramo, 2001.

DU RAP, André e ZENI, Bruno. Sobrevivente A ndré du R ap. São Paulo, Labortexto Editorial, 2002.

FERRÉZ. C apão pecado. São Paulo, L abortexto Editorial, 2000.

GU ASCO, Pedro Paulo Marques. N um país chamado Periferia: I dentidade e representação da reali dade entre os "rappers" de São Paulo. D issertação de M estrado, São Paulo, FFLCH -U SP, 2001.

J O CEN IR. Diário deum detento. São Paulo, Labortexto Editorial, 2001.

KEH L, M aria Rita (org.). Função fraterna. Rio de Janeiro, Relume D umará, 2000.

M EN DES, Luiz Alberto. M emóriasdeum sobrevivente São Paulo, Companhia das L etras, 2001.

M O NTEIRO, Danilo. SenhoresTempo Bom. A trajetória deThaídeeDJ H um, pi oneiros dohip hop brasileiro. São Paulo, U SP, 1999. Trabalho de conclusão de curso apresentado ao D epartamento de J ornalismo da E scola de Comunicações e Artes da U niversidade de São Paulo.

NESTROVSKI, Arthur e SELIGMANN-SILVA, Márcio (orgs.). Catástrofe e representação. São Paulo, E scuta, 2000. 
PIM EN TEL, Spensy Kmitta. O livrovermelho do hi p hop. São Paulo, U SP, 1997. Trabalho de conclusão de curso apresentado ao D epartamento de Jornalismo da Escola de C omunicações e Artes da U niversidade de São Paulo.

TELLA, M arco Aurélio Paz. A titude, arte, cultura e autoconhecimento: 0 rap como a voz da periferia. Dissertação de M estrado, São Paulo, PU C-SP, 2000.

VARELLA, D rauzio. Estação Carandiru. São Paulo, Companhia das Letras, 1999.

VIAN N A, H ermano. $O$ mundo funk carioca. Rio de J aneiro, Jorge Zahar, 1998.

Resumo - NESTE texto são feitas algumas considerações que partem de interesses e preocupações pessoais do autor a respeito do rap, tais como a elaboração das letras, a relação entre essa manifestação e o universo da pobreza e da prisão, o diálogo do ritmo com a tradição da música e da literatura brasileiras. São discutidas ainda algumas das questões estéticas e éticas relacionadas ao rap feito em São Paulo.

Aвstract - IN THIS text I set out some considerations that stem from keen personal interests and concerns regarding rap - e.g., the production of lyrics, the relationship between such manifestations and the universe of poverty and imprisonment, and the dialogue between this rhythm and the broader tradition of B razilian music and literature. I discuss some aesthetic and ethical issues related to the variety of rap that I am most intimately involved with, namely, the one made in São Paulo.

Bruno Zeni é jornalista formado pela E scola de Comunicações e Artes da U niversidade de São Paulo, mestrando em Teoria Literária e Literatura Comparada na Faculdade de Filosofia, Letras e Ciências H umanas da U SP; escritor, autor de $\mathrm{O}$ fluxo silencioso das máqui nas(AteliêE ditorial, 2002) e co-autor de Sobr evi venteA ndrédu R ap (L abortexto Editorial, 2002).

Texto recebido e aceito para publicação em 20 de fevereiro de 2004. 